\title{
Resetting Integrity Through Communication on Plagiarism: University Classrooms Weaving Values into the Social Fabric
}

\author{
Arniza Ghazali* and Azniwati Abdul Aziz \\ Universiti Sains Malaysia, Penang, Malaysia \\ https://orcid.org/0000-0002-9188-351X \\ https://orcid.org/0000-0001-8105-0701
}

\begin{abstract}
Academic dishonesty manifested in the proliferating acts of plagiarism can be eradicated by returning to value teaching. In a study involving 37 first-year students in one academic year, a single-group quasiexperimental procedure with mixed qualitative and quantitative analyses of students' assignments was performed. The procedure involved diagnosing plagiarism by strategic manual detection and classification of occurrences and recording the frequency of occurrence. The objective was to examine the effects of communicating about plagiarism by the designed plagiarism-integrity narratives (PIN) intervention on students' integrity based on their source-attribution practices. In the first semester, an assignment was administered without any word on plagiarism as the baseline data for students' academic integrity at pre-test. In the second semester, the post-PIN-intervention assignment set with similar cognitive demand as the first was administered. The post-PIN intervention showed $76 \%$ of students taking steps to not succumb to plagiarism, far outweighing the $5 \%$ not taking heed. Of those who acknowledged information sources, $14 \%$ showed excellent referencing skills, capturing the potential first-year role model. In terms of outsourcing and attribution combined, the PIN intervention offered a $95 \%$ transformation of moral values, hinting at the possibility of resetting academic integrity via communication and clear directives. Lifting plagiarism rules as a "litmus test" (third assignment) revealed $28 \%$ integrity-ready students applying the fundamental attribution rules. Outstanding referencing skills and honesty were portrayed by a selfregulated student who had internalized academic integrity. The findings signal the possibility of curbing plagiarism in university classrooms and nurturing students to start weaving values into the social fabric.
\end{abstract}

Keywords: integrity; higher education; plagiarism; values

\footnotetext{
*Corresponding author: Arniza Ghazali, arniza@usm.my
} 


\section{Introduction}

Executed by the Ctrl $+\mathrm{C}$ and $\mathrm{Ctrl}+\mathrm{V}$ functions of the computer keyboard, verbatim copying is the easiest and quickest way to commit plagiarism. Besides ease of execution, tips for by passing plagiarism detection software are also widely available, masking plagiarism misconduct and depriving human civilization from moral values and academic integrity.

\subsection{Plagiarism in the Academia - Distorted Learning Culture}

Plagiarism, the act of using an idea, work, or workpiece without proper attribution of the source or the creator was concisely marked by His Royal Highness Sultan Nazrin Shah, the Chancellor of Universiti Malaya, as an academic crime (Bernama, 2017). False claiming credits for others' work oppose academic integrity due to dishonoring intellectualism, creativity, and efforts. Within the locus of an innovative product, Williams (cited in Ibegbulam \& Eze, 2015) specified that others' "work" is inclusive of "creativity, ideas, and language" (p. 121).

First identified in the 18th century, plagiarism in academia has been trending (Perkins et al., 2020) and is projected to skyrocket with the growing scientific merit and competition (Visser et al., 2012). The onset of plagiarism coincides with the era of recognizing knowledge as a commodity (Zejno, 2018) and the number of output as impression for performance leading to titles and status. The desire for social recognition paired with an unwillingness to invest in resource-intensive learning and an ethical-succeeding process are two critical drivers for plagiarism. Tremayne and Curtis (2021) identified an impeded self-control as the underlying factor for dishonesty, explained in neuroscience as the silenced impulsive control from the frontal cortex (Watts et al., 2018).

The fluidity of plagiarism breeds endemic across the developing and developed world. The tendency to cheat has increased with online learning, although it is insignificantly prevalent among the more mature students (Ison, 2014). Artificial intelligence- (AI) wired plagiarism monitoring during online learning throughout the Covid-19 pandemic recorded a spike in cases. Analysis has shown that plagiarism was notable in science courses, higher in magnitude in the arts, and common practice in engineering courses (Davis, 2021). Lack of academic skills (Jereb et al., 2018), poor knowledge of plagiarism, and students' unawareness of learning expectations were additional driving factors to cheat "to level the playing field" (Davis, 2021, para 23). On the last note, Chan et al. (2014) regarded the phenomenon as a "social construct" (p. 120). Experts have reckoned that if unchecked, the criminal minds behind plagiarism could grow to become fraudsters, taxing a seventh of global gross domestic product (GDP), worth $£ 7.22$ trillion (Zee et al., 2016).

Graduates' confessions suggest that plagiarism has long plagued teaching, learning (Mohamed et al., 2018; Zejno, 2018), and research in Malaysia. In reality, the phenomenon manifests itself as countless educational stigmata, diffusing into the social fabric. The ripple effect was marked explicitly by Royal Professor Ungku 
Abdul Aziz Abdul Hamid that "the teaching and learning process are the fundaments in effecting the woes faced by society" (Azahari \& Ramjit, 2008, para 6).

Malaysian junior youths performing below par globally (Cheah, 2015; Kok, 2020; Perera \& Asadullah, 2019; Tan et al., 2019) mirrors the distorted learning culture. Poor learning skills, which lead to plagiarism or vice versa, attests to the argument that "[p]lagiarism breeds poor study habits" (Ibegbulam \& Eze, 2015, p. 122). The phenomenon raised bears concerns over its repercussion on education quality due to the circular nature of human capital - a student last decade, a teacher in the present time. Although factors behind poor performance vary, plagiarists among the educational workforce are more likely to repeat their undergraduate dishonesty at work (Payne \& Nantz, 1994). The great concern is that such misconduct will be passed on as a survival tip to the succeeding generation.

Thus, when the $60 \%$ of Malaysian graduates (Table 1) are compared with the meager $28 \%$ of Malaysian parents possessing a tertiary education qualification (Perera \& Asadullah, 2019), this figure reveals that only $10 \%$ of guardians possess authentic learning experience.

Table 1: Self-reported plagiarism cases and stance for a specific penalty by locality or nationality

\begin{tabular}{|c|c|c|c|}
\hline Period & $\begin{array}{c}\text { Cases by } \\
\text { locality/nationality }\end{array}$ & $\%$ & Reference \\
\hline 1940s & United States of America & $20 \%$ & McCabe $(2006)^{*}$ \\
\hline 1990s & United States of America & $90 \%$ & McCabe $(2006)^{*}$ \\
\hline 1999 & Duke University & $10 \%$ & McCabe $(2006)^{* *}$ \\
\hline 2003 & Rutgers University & $38 \%$ & $\begin{array}{l}\text { Rutgers University } \\
(2003)^{\star *}\end{array}$ \\
\hline 1999-2009 & Malaysia & $60 \%$ & Dannian (2009) ${ }^{* *}$ \\
\hline 2012 & Nigeria & $60 \%$ & Babalola $(2012)^{* *}$ \\
\hline 2013 & Portsmouth & $54 \% * * *$ & Ubaka et al. (2013)*** \\
\hline 2004-2019 & Australia & $\begin{array}{l}60- \\
80 \% \\
\end{array}$ & $\begin{array}{l}\text { Tremayne and Curtis } \\
\text { (2021) }\end{array}$ \\
\hline 2015 & Nigeria & $44 \%$ & Ibegbulam and Eze (2015) \\
\hline Until 2010 & Various nations & $61 \%$ & Dante $(2010)^{* * * *}$ \\
\hline \multicolumn{4}{|c|}{ Stance with regard to plagiarism penalty } \\
\hline Favor penalty & Nigeria & $44 \%$ & Ibegbulam and Eze (2015) \\
\hline Favor penalty & Malaysia & $41 \%$ & Zejno (2018) \\
\hline For expulsion & Nigeria & $18 \%$ & Ibegbulam and Eze (2015) \\
\hline
\end{tabular}

The proportion is only about a third of the figures reported by Perera and Asadullah (2019) for Korea (57\%) and Singapore (47\%).

The underperformance of locals in the Programme for International Student Assessment (PISA) (Perera \& Asadullah, 2019) and Trends in International Mathematics and Science Study (TIMSS) (Phang et al., 2020) has a direct link to the poor teaching and learning practices. Malpractices such as the leaking of 
examination questions and memorization of essays instead of teaching writing processes advance plagiarism as an educational issue. Resetting academic integrity is therefore a priority to break the cycle of the known record of best-performing Malaysian students failing in the Singaporean education assessment system (Tan et al., 2019).

In higher education, the effects of academic misconduct are outrageous and twosided. While the prey (students and/or staff) suffer silenced agony, depression, or withdrawal (Clark \& Wallace, 2018), the predators (the plagiarists) amass false credits, productive impressions, position, and an exhaustive recognition list that attracts allies. In research publications, collusion can occur through various "research briberies" disguised as "success strategies". False authorship in exchange for a student's monthly stipend offered by a researcher not recognized as the actual working team, for instance, is a vivid form of plagiarism, and plagiarism is a violation of research integrity (Garcia-Carbonell et al., 2021; Labib et al., 2021). Unfortunately, the misbehavior generates an impressive list of selfclaimed scholarly works "harming scholarship" (Clark \& Wallace, 2018, p. 133) and producing like-minded graduates who then operate the various segments of the education sector.

\subsection{Problem Statement}

Although plagiarism is a distortion, it is unfortunately not acted upon, with the view to be "humanitarian" towards students. As such, plagiarism is regarded insignificant by the university community under study. As students advance in their university years, they confuse plagiarism with a Turnitin ${ }^{\mathrm{TM}}$ similarity index (TSI), their scores often exceeding 30\% without realizing that this figure indicates an outright counter-integrity nature of 30\% tolerance of detectable pathologic cheating. TSI as plagiarism metrics can be manipulated by changing terms and words to bypass the text-match algorithm. While plagiarism persists, students' assignments are approved for grading. A stringent TSI setting serves better to ensure quality learning. The $1 \%$ tolerance embraced by Batane (Ison, 2014), a professor in instructional technology, has also been embraced by other academics, who fear the repercussions from undermining morality and the ultimate paralysis of the nation-building agenda. It is apparent, thus far, that despite $\mathrm{AI}$ and the conquest of technology-driven services, educators remain the most well-suited to engender value education by detecting and rectifying the situation. The mission sheds light on the remedy of the system, commensurate with the study's objectives.

\subsection{Objectives}

Strategic manual tracking of plagiarism involving ideas, texts, and visuals was performed on three batches of assignments in a single-group quasi-experimental study with a pre- and post-test to achieve these objectives:

i. to determine if plagiarism exists among 2020/2021 first-year students;

ii. to identify the types of plagiarism versus percentage of students committing plagiarism; and

iii. to assess if communicating plagiarism with students by the designed plagiarism-integrity narratives (PIN) intervention could drive behavioral changes. 


\subsection{Research Questions}

In the quest to achieve the research objectives, we have formulated three specific questions:

i. Does plagiarism happen among 2020/2021 fresher students enrolled in the selected course?

ii. What are the plagiarism types versus the percentage of students involved?

iii. How does communication about plagiarism (by PIN intervention) affect the trend in students' attribution of information sources?

\section{Methodology}

\subsection{Research Design}

A single-group pre-test and post-test quasi-experimental design was employed. The study integrated mixed qualitative and quantitative analyses (Figure 1) of students' plagiarism behavior, adhering to the principles of the Scholarship of Teaching and Learning (SoTL) research described by Miller-Young and Yeo (2015).

The methodological framework adopted for this study is summarized in Figure 1 and will be discussed below.

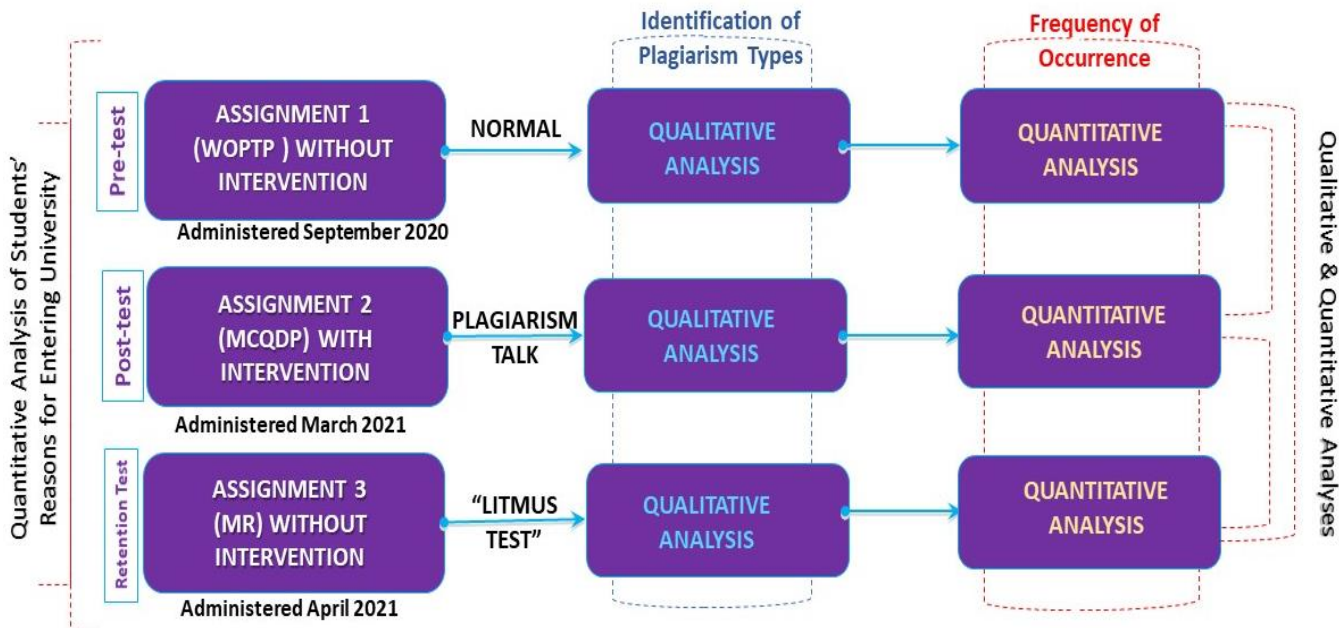

Figure 1: The mixed qualitative-quantitative framework adopted in the single-group pre-test-post-test quasi-experimental design

\subsection{Participants and Course Materials}

In the first semester of the 2020/2021 academic year, the portion of the university course titled Basics of Materials Analysis was presented synchronously via Webex ${ }^{\mathrm{TM}}$ and deposited as micro-credential modules in Universiti Sains Malaysia's OpenLearning ${ }^{\mathrm{TM}}$ platform. The materials acted as a primary reference to the students enrolled in the course. The study's focus was the cohort constituting 37 first-year students from the Division of Bioresource Technology (BRTech). At the time of study, the students were between 20 and 21 years of age from the bottom 40\% (B40) and middle 40\% (M40) income groups. 


\subsection{Learning Resources Strategized for Plagiarism Detection}

Consistent in all cases, rich learning resources were availed to the students. The resources were deposited in Universiti Sains Malaysia's OpenLearning ${ }^{\mathrm{TM}}$ platform and as e-books presenting active and inactive links to the recommended industrial and academic references. The created e-books contained "hidden" grammar and spelling mistakes to ease tracking of plagiarism. Exaggeration of reference listing was detectable as the instructor-cum-author cited hardcopies of the personally subscribed industrial newsletters. Mishandling of artwork not detectable by such plagiarism software as Turnitin ${ }^{\mathrm{TM}}$ was also possibly detected as most images were digitally drawn by the instructor to represent ideas formulated from numerous references. Related e-books were made available at an online platform with analytics recording access. All digital learning materials were accessible on and storable in students' smartphones in favor of Gen Z's preference (Annamalai et al., 2021).

\subsection{Data Collection}

Students were assigned higher order thinking tasks requiring analysis of learning materials and synthesis of ideas. The resultant monitoring time was between September 15, 2020 and July 15, 2021, totaling one academic year.

\subsubsection{Pre-Test}

In the first semester, students formulated ideas and presented a video and script proposing the actions required to investigate "why the orange pumpkin turned purple (YPTP)". The essential requirement was to indicate team member contribution and sources of ideas. No instruction on plagiarism was given.

\subsubsection{Post-Test and Plagiarism-Integrity Narratives (PIN) Intervention}

A briefing on the semester two assignment explicitly instructed students to formulate ideas on a poster related to the multiple-choice question (MCQ) paired with the related descriptive question. The MCQ-descriptive paired question is from here onwards abbreviated MCD or Assignment 2. Students were introduced to plagiarism and why it reflects integrity and should never be regarded as "a small matter" (Table 2). As guidance was given on MCD, the instructor recommended that students indicate the sources precisely, as shown on lecture slides, OpenLearning ${ }^{\mathrm{TM}}$ modules, and e-books. No strict rules on correct paraphrasing or format were set. The main goal was to inculcate academic integrity by honestly stating the source or reference used from which the ideas formulated on the poster were derived. The gist of the communicated narratives is presented in Table 2.

Table 2: Plagiarism-integrity narratives (PIN) as an intervention in communication on plagiarism

\begin{tabular}{l|l}
\hline What is plagiarism & \multicolumn{1}{l}{$\begin{array}{l}\text { Basic definition and types in Ghazali (2021) and } \\
\text { Nabee et al. (2020) }\end{array}$} \\
\hline $\begin{array}{l}\text { How plagiarism ties to } \\
\text { integrity }\end{array}$ & $\begin{array}{l}\text { Quoted a statement by a popular, reputable, and } \\
\text { civilized figure and their academic qualification. } \\
\\
\end{array}$ \\
& $\begin{array}{l}\text { The instructor also related plagiarism to a Malay } \\
\text { proverb, "Lembu punya susu sapi dapat nama." The } \\
\text { proverb depicts an ironic situation of a person }\end{array}$ \\
\hline
\end{tabular}




\begin{tabular}{|c|c|}
\hline & $\begin{array}{l}\text { gaining credit from someone else's work by an } \\
\text { analogy of a cow producing milk, but the oil } \\
\text { produced from the milk is sapi's oil. In Malay, } \\
\text { lembu and sapi are synonymously used for cow. }\end{array}$ \\
\hline Consequences & $\begin{array}{l}\text { Global record for penalties on plagiarists: } \\
\text { - } \text { high-ranking officers; politicians, and a } \\
\text { rector, } \\
\text { - } \text { students from selected international } \\
\text { universities, } \\
\text { - Malaysian candidate denied a PhD from a } \\
\text { UK university for not attributing his } \\
\text { supervisor's ideas. }\end{array}$ \\
\hline
\end{tabular}

\section{5 "Litmus Test" for Academic Honesty}

The students' academic honesty was further tracked in the third assignment requiring them to formulate ideas and write a one-page (A4) media review, abbreviated MR or Assignment 3. The writing assignment was given without any referencing instruction. Plagiarism rules were lifted, and students' honesty in crediting ideas, facts, and figures was monitored.

\subsection{Analysis}

Qualitative analysis was employed by going through each submitted assignment to identify plagiarism involving visuals, ideas, and collusion, which was not detectable by Turnitin ${ }^{\mathrm{TM}}$. Imperfections in rephrasing were tolerated. Plagiarism types were classified, counted, and the percentage was calculated as per the total number of participants.

Supplementary data capturing the students' learning goals were acquired using the 13th item in the survey embedded in the Universiti Sains Malaysia micro-credential module titled Fundaments of Plagiarism at https://learning4life.usm.my/courses/fundaments-of-plagiarism.

The candidate who achieved the best attribution practices was contacted to talk informally about the reasons behind their determination to avoid plagiarism. The communication took place via WhatsApp messaging as the semester break started.

\subsection{Terminology}

The quantitative analysis of assignments submitted by students had a particular trend of referencing issues. Table 3 defines each classification used as labels on the graphics in section 3 (Results). Note that the qualitative analysis was solely for research and future strategic actions. Students were not severely penalized for plagiarism or incorrect referencing as the aim of the assignments was to track their ability to grasp the course while learning to apply academic honesty. 
Table 3: Attribution labels by issues

\begin{tabular}{l|l}
\multicolumn{1}{c}{$\begin{array}{c}\text { Attribution labels } \\
\text { (status in bracket) }\end{array}$} & $\begin{array}{l}\text { Criteria \& issues } \\
\text { entirety, with or without removing words; } \\
\text { changing tense; or modification in the case } \\
\text { of visuals. }\end{array}$ \\
\hline $\begin{array}{l}\text { 1. Verbatim plagiarism } \\
\text { 2. Fake list/citation } \\
\text { (dishonesty/erroneous) }\end{array}$ & $\begin{array}{l}\text { "Fake list/citation" refers to a mismatch } \\
\text { between the references cited in-text and the } \\
\text { ones listed. Points described differently } \\
\text { from those in the listed references are also } \\
\text { considered a mismatch. }\end{array}$ \\
\hline $\begin{array}{l}\text { 3. List only } \\
\text { (erroneous) }\end{array}$ & $\begin{array}{l}\text { The listed references match the presented } \\
\text { facts, thus not regarded as dishonesty, but } \\
\text { still in the domain of plagiarism. An } \\
\text { exaggerated list is considered dishonesty. }\end{array}$ \\
\hline $\begin{array}{l}\text { 4. Skilled referencing } \\
\text { (commendable) }\end{array}$ & $\begin{array}{l}\text { The references are cited in the text and } \\
\text { listed accurately with or without an } \\
\text { elaboration. }\end{array}$ \\
\hline $\begin{array}{l}\text { 5. Surface knowledge I } \\
\text { (lack in learning effort) }\end{array}$ & $\begin{array}{l}\text { The presentation contains misinterpreted } \\
\text { points from the lecture materials - no } \\
\text { outsourcing of the recommended } \\
\text { references. }\end{array}$ \\
\hline $\begin{array}{l}\text { 6. Surface knowledge II } \\
\text { (favored when instructed) }\end{array}$ & $\begin{array}{l}\text { Closed-book examination types of correct } \\
\text { answers not requiring citation or reference } \\
\text { listing. Students digested the course } \\
\text { contents and linked various points from the } \\
\text { syllabus. }\end{array}$ \\
\hline favored) & $\begin{array}{l}\text { In-text citations complying with the format } \\
\text { recommended by the instructor. }\end{array}$ \\
\hline
\end{tabular}

\section{Results}

\subsection{Baseline Data from the Pre-Test}

At the start of their fresher year, $76 \%$ of the students went the extra mile with literature searches in the problem-solving assignment, while the rest were comfortable presenting surface knowledge (I and II) (Figure 2a). No student adopted the minimal referencing demonstrated in lecturer materials despite accessing and using the references. In outsourcing facts and figures, $42 \%$ of the students neither cited nor listed the references, 9\% presented contradicting citations and reference listing, while $21 \%$ listed their references without in-text citations (Figure 2b). While correct surface knowledge (II) was given marks for accuracy, attribution of sources was essential for an assignment with multiple reference repositories and offered a multiple-day working duration. Applying a stringent rule could have placed all students on the brink of plagiarism. 


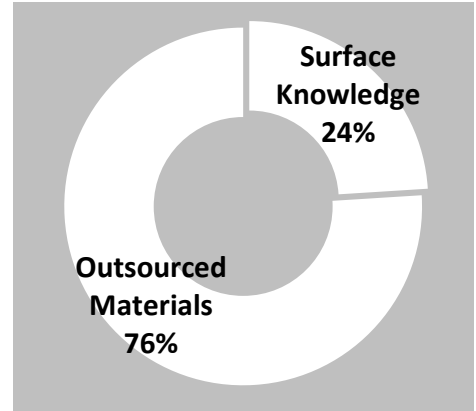

(a)

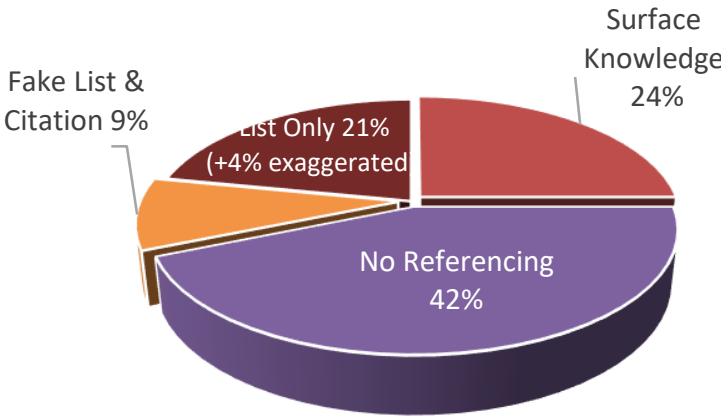

(b)

Figure 2: Students' handling of assignment 1 (why the orange pumpkin turned purple [YPTP]) differentiating (a) commitment and (b) source attribution profiles

\subsection{Baseline Data from the Post-Test}

The submitted MCD on the concepts of zero-waste biomass management shows that 95\% (Figure 3a) of the students went the extra mile to analyze the given materials and outsource the recommended references. The change in attribution profile is also positively apparent, indicating a majority attempting to declare the references they used, giving an honest list of references and less recall-type answers post-PIN intervention. As opposed to the presentation of misleading surface knowledge, students engaged in more reading and outsourcing and attributed the references accordingly. The PIN intervention shifted the trend in students' referencing and outsourcing positively, with higher records for honesty and simultaneously zeroing down the fake listing of references.

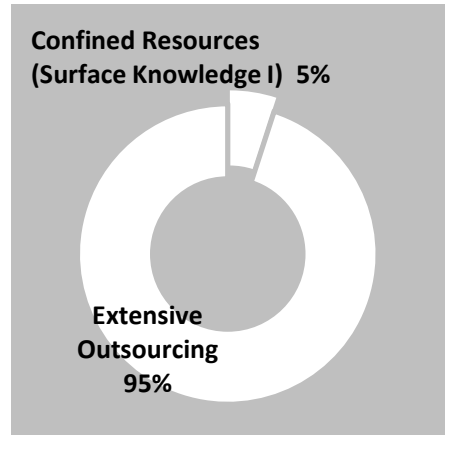

(a)

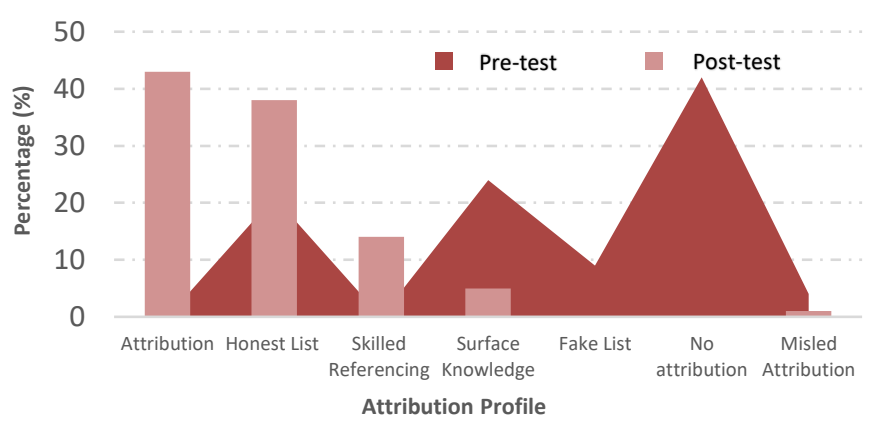

(b)

Figure 3: Students' handling of reference attribution after PIN intervention showing (a) 95\% of students outsourcing for references and (b) comparison of referencing practice with baseline data

The $5 \%$ of students who chose to present surface knowledge (Figure $3 \mathrm{~b}$ ) defeated the purpose of higher order thinking skills required of the poster construction. These students missed the processes of linking and translating the formulated ideas into graphics. The targeted cognitive exercise was also misunderstood by one candidate as mere "cartoon time", as shown on the student-given filenames. Competing duties from extra-curricular activities and a spiking volume of assignments could be factors that slowed down participation in semester 2's WhatsApp interaction. The disengagement was typical of the few who seek soft 
skills from co-curricular activities. Among those who invested tremendously in the poster construction, $43 \%$ attributed the references as per the minimal recommendation from the instructor, and 14\% skillfully cited the sources, amounting to $57 \%$ adhering to the minimal referencing guidelines set by the instructor (Figure $3 b$ ).

With the attribution rules in place, the students in the change-resistant group, who believed that reference-listing was the means to avoid plagiarism, increased from $20 \%$ to $38 \%$ (Figure $3 \mathrm{~b}$ ). The situation could have been aided if students had consulted the course instructor for guidance. The numbers demonstrate Asians' (Anyanwu, 2004) misconception of reference-listing to rule out plagiarism, seeming deep-seated or deceptively well-received. Despite the error, the absence of a fake exhaustive list and the distinctive match between presented ideas and listed references indicate enhanced academic honesty.

Unexpectedly, $14 \%$ of the students presented skilled attribution of sources, while two candidates in the group cracked the code for space-economy referencing. By opting for the Vancouver referencing system, these two managed to do in-text citations and list the sources.

\subsection{Baseline Data from the Litmus Test}

The third assignment, denoted MR or Assignment 3, was administered before the semester ended and required the students to read the recommended laymen article, identify the issue, and relate it to the course contents. As a basic assignment presentation practice, the essential references deposited at the university's OpenLearning ${ }^{\mathrm{TM}}$ portal and the recommended article were cited and listed appropriately in students' write-ups.

It turns out that when decision autonomy for source attribution had been transferred to the students, $28 \%$ adhered to the basic referencing rules (Figure 4), expanding the "count of honesty" captured in Assignment 2 twofold.

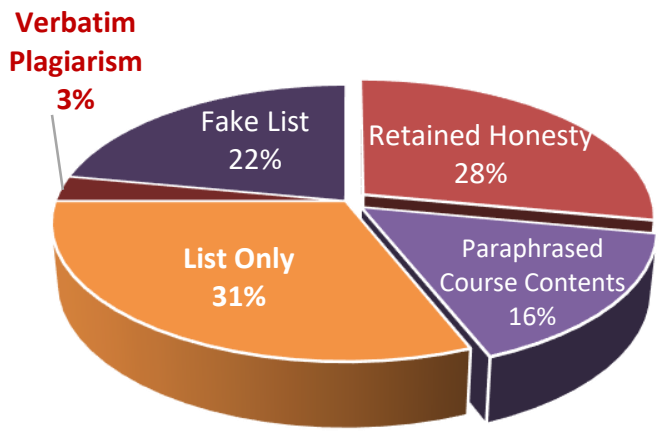

(a)

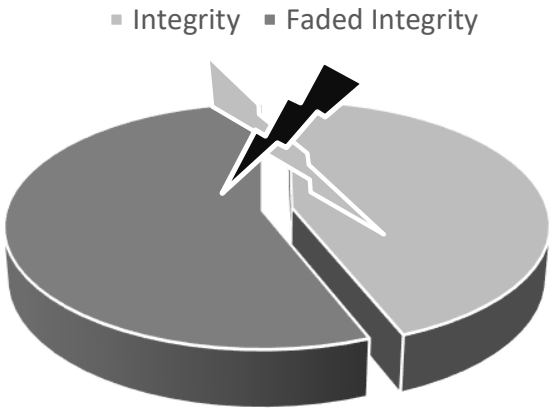

(b)

Figure 4: Students' (a) referencing practice in the absence of plagiarism rules, yielding (b) a stringent divide between students with integrity and those with faded integrity

B40-2 and M40+, two candidates in the B40 and M40 groups, respectively, complied with referencing for undermining plagiarism by wonderfully applying 
the APA referencing system. M40+ informed the instructor of the decision for retaining some of the sentences in their original form. This was based on the need to permit, temporarily at least, the "error tolerating culture" (Labib et al., 2021, p. 6) to encourage fresher students to openly share their circumstances and feel safe about making mistakes during the learning period. Unlike B40-1, who abandoned proper referencing once plagiarism rules were lifted, both B40-2 and M40+ prevailed in attributing ideas despite their equally hectic study schedules. Students may have associated the firm determination to uphold academic integrity with their fear for long-term enculturation of dishonesty and fear for failure due to plagiarism as contained in intrinsic and extrinsic motivations. On this note, M40+ expressed: "Doctor reminded that it is wrong to take credit for others' ideas. I want to do the right thing," portraying a reasonable degree of integrity leadership. The case also relates well with earlier findings that plagiarism is affected by students' level of understanding (Nabee et al., 2020; Tremayne \& Curtis, 2021) and internalization (Labib et al., 2021) of plagiarism and its impact. Beyond comprehending the issue, M40+ internalized the need to abandon the misconduct for the long-term divine blessing mentioned extremely briefly by the instructor in reference to a specific section of the holy book of Islam (the Quran), while welcoming similar input from other religions.

Students were asked to explain why they chose to pursue education at the university level. The results are depicted in Figure 5.

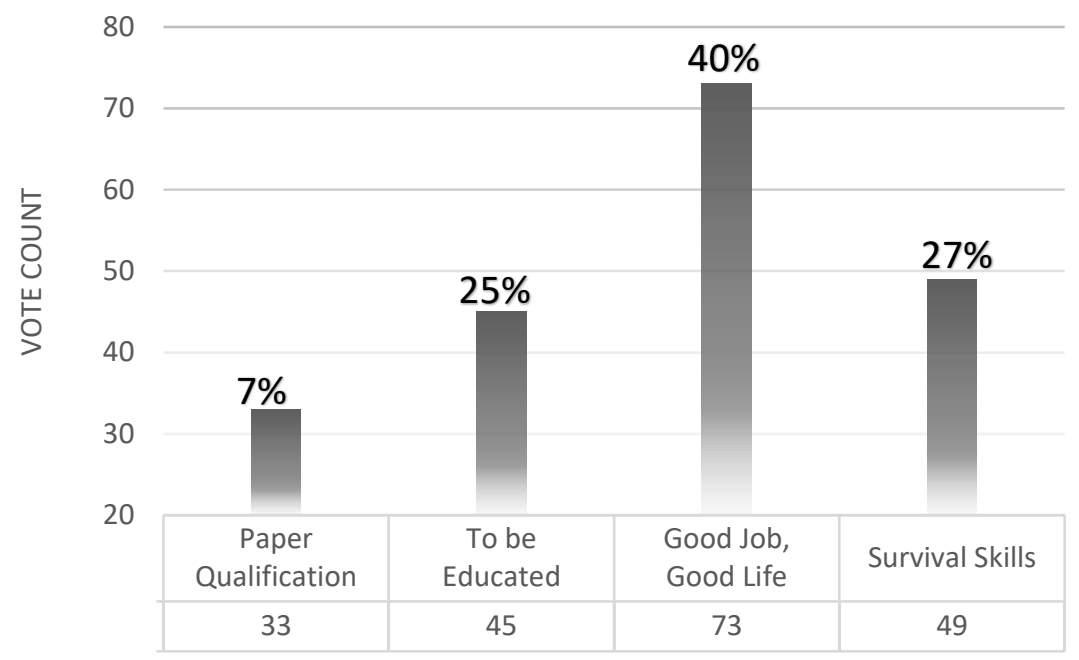

Figure 5: Self-reported reasons for entering university

Twenty-five percent of the students indicated that to be educated was their primary reason for entering university (Figure 5), which signals transformation by gradual improvement (in the case of $\mathrm{M} 40+$, particularly). Students whose goal gravitates towards "good job, good life" may be less committed and usually avoid painstaking tasks, cutting corners to quickly exit the system for a job, by all means. The priority set by this group is passing rather than subject mastery, a typical self-reported reason for plagiarism reported by Jereb et al. (2018) for selected European nationals. Considering the mentioned moral self-image concept and Ajzen's Theory of Planned Behavior, it becomes self-explanatory that the $14 \%$ who 
meticulously strove to reference correctly were among the B40 group and those who were pleased to abide by morality.

\section{Discussion}

\subsection{Norm \& Alert for Educators}

The study provides evidence of plagiarism, the known hindrance to academic goals that would otherwise remain silenced. Paralyzing policies and educational practices that directly or indirectly tolerate plagiarism need to be scrutinized to halt its proliferation. Among the practices are:

i. Setting too high a text-matching similarity index such as TSI as a prerequisite for passing an assignment or as a gauge for readiness for submission and grading.

ii. Teaching students the trick to bypass the text-matching algorithm of plagiarism detection software by changing words. Not only has the trick acclimatized students to verbatim plagiarism, but it has also contributed somewhat to the plateauing trend in plagiarism cases, as captured by Curtis and Tremayne (2021).

iii. Allowing leniency to retain a $100 \%$ pass rate by availing opportunity for work resubmission and appointment of a new examiner when plagiarism is reported.

iv. Silencing cases to avoid the tedious regulatory procedure.

v. Exempting senior academics from integrity education when it is available or lacking intervention to actualize academic integrity education, which should by right be for all involved in scholarly communication.

vi. Recognizing output numbers or assessing only the output over the more timely knowledge-skills-abilities (KSA) assessment tool proposed by Garcia-Carbonell et al. (2021).

On the last note, the number of graduated students and the number of publications students have their names on (rather than assessing if the academic communication skills have been acquired) can be non-cognitive achievements. As much as it is an issue to address for learners, assessing skills is timely for educators, as illuminated by integrity experts such as Garcia-Carbonell et al. (2021), to suit the unique demand of the present time (Powell, 2021).

Lack of integrity captured in the baseline data plunged students into verbatimcopying plagiarism, outright dishonesty, and low morality, which could be fixed by learning the correct way of presenting ideas. Unlike the trends in other nations (Curtis \& Tremayne, 2021) within this study's radar, the verbatim plagiarism led to improper referencing stemming from under-nurtured integrity and poor mastery of the instructional medium. Long-term tolerance of the error would aggravate the situation, engendering the clear divide between integrity learners and the "faded integrity" group (Figure $4 \mathrm{~b}$ ), with the latter outnumbering the desired former.

Changing words and tenses were also actions taken to hide verbatim plagiarism. The findings share a commonality with an earlier study led by forensic linguist Sousa-Silva (Sousa-Silva et al., 2010). Word changes may escape a text-matching 
algorithm but still count as plagiarism, marking one other loophole associated with plagiarism detection software, its approval of tricks and its improper use as a tool to inculcate moral values. The findings call for human teachers to play a role in integrity education and the need to define precise limits to the relevance of plagiarism software to halt the distorted learning culture.

Fine detailing of verbatim plagiarism was captured in the inappropriate use of scientific visuals. One of the instructor's figures was used without basic attribution such as "Reproduced from (source) with alteration". Instead, one student claimed: "Illustration hand drawn by (student's name) on iPad Ms PowerPoint." Such error is marked as "misled attribution" in Figure 3b. The student succumbed to plagiarism by undervaluing the volume of intellectual skills required to research and connect the complex science involving biochemistry, geochemistry, and inorganic chemistry with an industrial feedstock. The incident is reminiscent of the Malaysian student who was denied a PhD in a UK educational institution for undermining the supervisor's idea as common knowledge and not attributing the idea. The fact that the student was among the top three in the course suggests that language mastery alone is insufficient. Integrity and moral values are critical factors for teaching instructional and communication media for meaningful learning. In a similar vein, Briggs (cited in Anyanwu, 2004) illuminated:

"The problem with the moralistic attitude underpinning policies of plagiarism is that such moralism is so institutionalized - and so easily offended - that we are prone to forget the very straightforward and obvious idea that plagiarism constitutes a learning and communication problem too." (p. 184)

The findings also signal the more technical measure for curricular improvement. Education prior to tertiary level should serve as a preparatory program. The missing, unachieved learning outcome creating a performance gap signals the need to retrain educators and re-examine their work scope. Focus on integrity or value education should prepare teachers to communicate PIN messages customized to their target group. Policing plagiarism (Stabingis et al., 2014), formerly mandated to educators by experts, lie detection, and reformatting tasks are programmable with AI. However, every opportunity to communicate PIN, whether in curricular or extra-curricular activities, should be maximized by human educators. Given the outcomes-based education system already in place, actualizing integrity narratives into outcomes should be an enjoyable task and not an additional burden to teachers. Integrity education should better prepare teachers for the next skill-demanding level for mitigating language for ethical communication courses. The strategy is necessary as students' aptitude in the instructional media correlates with good learning (Ghazali \& Ghazali, 2020; Ibegbulam \& Eze, 2015; Kok, 2020). The course in itself is the powerful preparatory channel to actualize good learning and integrity education. As Thomson (cited in Davis, 2021) illuminated: "There's no need to cheat when you're having good learning" (para 17)

Mastery of the communication media assists, to a great extent, in preventing cheating. On a neuro firing scale, plagiarism can be prevented by the ability to think (cognitive, C) with self-control, evaluate, weigh the underlying effort, and 
responsibly honor (affective, A) idea sources by proper attribution (behavioral, B). These are learning variables that occur in equilibrium at varying skill levels and domains. The continuous triple-domain interaction is condensed in equilibrium equation 1:

$$
\mathrm{A}+\mathrm{B} \rightleftharpoons \mathrm{C}
$$

\section{Self-control}

The higher order thinking skills which can be learned and mastered through writing tasks are in line with the scholarly view on achieving educational goals strategized (Drach \& Slobodianiuk, 2020). Regarding this, Tulus (2020) posited: "The purpose of written projects and schoolwork is to help students think, create and communicate critically in writing. If we plagiarise, we bypass this educational goal" (p. 4).

Through its Civil Services Department, Malaysia has spent billions grooming critical intellectual mass through education and training abroad. Survival in stringent systems has equipped graduates to understand the link between plagiarism and the impeded achievement of educational goals. Dialogues on mitigation should include the group revisiting the goals set in the National Higher Education Strategic Plan (NHESP) (see Table 4). The NHESP targeting the generation of a first-class mindset is the profound reason for initiating integrity education. The mission is mandatory in the phase of "developmental challenges in knowledge and innovation-based economy" (Mohamed et al., 2018, p. 248).

\section{Table 4: NHESP key thrusts}

\begin{tabular}{l|l} 
Phase & Key thrust \\
\hline $\mathbf{1}$ & Laying the foundation (2007-2010) \\
$\mathbf{2}$ & Strengthening and enhancement (2011-2015) \\
$\mathbf{3}$ & Excellence (2016-2020) \\
$\mathbf{4}$ & Glory and sustainability (2020 and beyond) \\
\hline
\end{tabular}

Relaying the foundation through integrity education will aid in redefining excellence, placing plagiarism as an essential predictor on the radar. It is also alarming that Malaysia is nowhere near advancing from Phase One of the NHESP key thrusts (Table 4). Marking an action in the timeline sheds light on the possibility of achieving the good a decade from now.

\subsection{Plagiarism-Integrity Narratives Dosage Lesson from the Litmus Test}

The students' readiness to comply with the appropriate work standards suggests that plagiarism is rectifiable through simple narratives. We coded the two best candidates for referencing practice as B40-1 and B40-2. They are the glaring evidence of self-regulated learners (SRLs) with the skills to take complete strategic control of learning and achieving the goal, meeting the SRL definition set by Anthonysamy et al. (2021). The fact that the portion violating academic integrity outnumbers those respecting academic integrity calls for continuous efforts to detect and prevent plagiarism (Curtis \& Tremayne, 2021). In a less formal setting, there is a need in integrity education to deploy PIN intervention repetitively in various creative ways and enforce an "error accepting culture" (Labib et al., 2021, p. 6). 
PIN intervention, simple and doable at zero cost, should be accessible to all who desire to relearn moral values. A formal first input can be suitably administered to the fresher students across all courses to ensure a consistent call to uphold moral values. The frequency can be lessened but sustained once enculturation has been achieved. More experts can participate in the dialogue to empower the narratives so that PIN can touch more hearts, even of the recalcitrant 3\% (Figure 4a) experiencing "amotivation". On that note, Ryan et al. (2009) described amotivation as a phenomenon arising from the instruction-outcome disconnection due to the intangible nature of the outcome of being either honest or dishonest. Doing good only when policed and ignoring rules without law enforcement resemble a thirdworld mindset. Fear for a penalty as an extrinsic motivation or intention for recognition (Ryan et al., 2009) can also be used as intervention for enhancement to rule out reported license-to-cheat thinking (e.g. "getting caught [is] negligible") addressed in the literature (Nabee et al., 2020, p. 66). The value-teaching strategy is also of no discord to "encourage people to live according to higher ethical standards", as reckoned by Ayal et al. (2016, p. 1521) from a broader dishonesty perspective.

\subsection{Plagiarism-Integrity Narratives for Taming the Brain}

In the discussion on behavior, Zejno (2018) associated religiosity with the manifestation of academic integrity. The account on religiosity also guides one's delineation between right and wrong and the courage to be amanah (trustworthy) or, in contrast, to disservice the nation, in line with Bukuri's analysis of Ajzen's Theory of Planned Behavior (Zejno, 2018). In moral self-image sciences, Jordan et al. (2015) rationalized "internalized moral identity as a stable trait" (p. 22), and the moral trait manifested by B40-2 and M40+ reflects the identity of morality preached in the Islamic and other divine teachings (Scott, 2021). In this regard, M40+ asserted that she tried to avoid what the instructor communicated as wrong (to prevent plagiarism and cheating from becoming her habit), and her effort points to a determined attempt at morality. Equally important is a notion shared by an expert in change leadership, Scott (2021), who illuminated that people are willing to change when such criteria as reliability, feasibility, clarity, desirability, relevance, and values are portrayed in the directives. Emphasizing values being the "engine house of change", Scott (2021) also posited that values are linked to the world's religions and underpin the lives of successful graduates and leaders.

The abstract nature of religiosity is backed up by the science of brain response. In this regard, Tremayne and Curtis (2021) associated integrity and moral compass with being governed by self-control. Imaging technology mapped the origin to specific brain functions (Watts et al., 2018), suggesting the requirement of conditions to enculturate value instructions into practice.

The deployed PIN intervention should be dialogued for improvement and enforced through policy, as also recommended in earlier findings:

"Plagiarism has no borders. The cases of plagiarism could be found in students' written works around all over the world, but more numerous cases could be met in countries having comparatively poor legal regulation on copyright and quality of studies as well as in higher education institutions missing ethical norms, policies, and procedures on plagiarism prevention. But most sad is missing of open and wide 
discussion on this issue in academic communities." (Stabingis et al., 2014, p. 690)

\section{Conclusion}

The strategized manual tracking of plagiarism through several learning resources created by the course instructor served as the diagnostic tool sensing plagiarism among the 2020/2021 fresher students of the Bachelor of Technology program. The assignments submitted at the pre-test stage showed the normality of plagiarism in students' work. Communication about plagiarism, its ties to integrity, and its implications via the PIN intervention employed increased students' outsourcing for references and attribution of the sources to $95 \%$. The behavioral changes reflected the transformation of moral values and enhanced academic honesty. This proves that specific narratives in a brief communication about plagiarism could impact academic practices and integrity. The students who cracked the code for the space-saving referencing technique and those who continued to avoid plagiarism when rules were lifted were potential trendsetters and agents to echo academic integrity. Students were willing to change, mainly when they had clearly understood the instruction and outcome. Among the $28 \%$ who honestly attributed reference sources, one candidate internalized plagiarism as academic misconduct and chose not to act against moral values even when plagiarism rules were lifted. Students abandoning integrity outnumbering those who retained honesty suggests that PIN intervention should be deployed repetitively at the right intervals. The prevalence of verbatim plagiarism alerted us to revisit the NHESP for its profound actualization using the unoptimized resources. The shared behavioral transformation and learners' willingness to meet standards shed light on the possibility of resetting integrity in university classrooms to weave moral values into the social fabric.

\section{Acknowledgement}

The presented Scholarship of Teaching and Learning (SoTL) research is part of a continuous effort to improve students' learning commensurate with the United Nations' fourth sustainable development goal (SDG4), instructing quality education.

The data in this presentation could not have been acquired without input from the Program Chair, Associate Professor Dr Leh Cheu Peng, to whom big thanks are due.

\section{References}

Annamalai, N., Mažeikienè, V., Tangiisuran, B., \& Oleskevicience, G. V. (2021). How do students really interact? An investigation of Lithuanian students' interactions via smartphone apps. Malaysian Journal of Learning and Instruction, 18(1), 65-83. https:// doi.org/10.32890/mjli2021.18.1.3

Anthonysamy, L., Ah-Choo, K., \& Soon-Hin, H. (2021). Investigating self-regulated learning strategies for digital learning relevancy. Malaysian Journal of Learning and Instruction, 18(1), 29-64. https:// doi.org/10.32890/mjli2021.18.1.2

Anyanwu, R. (2004). Lessons on plagiarism: Issues for teachers and learners. International Education Journal, 4(4), 178-187. https://eric.ed.gTTov/?id=EJ903820

Ayal, S., Hochman, G., \& Ariely, D. (2016). Dishonest behavior, from theory to practice. Frontiers in Psychology, 7, 1521. https:/ / doi.org/ 10.3389/fpsyg.2016.01521 
Azahari, N. H., \& Ramjit. (2008, December 1). Malay poverty and education, the lifelong agenda of Ungku Aziz. Din Merican: The Malaysian DJ blogger. https://dinmerican.wordpress.com/2008/12/04/ungku-a-aziz-a-humanistand-educationist/

Bernama. (2017, November 18). Plagiarism is an academic crime, says sultan of Perak. The Sunday Daily. https://www.thesundaily.my/archive/plagiarism-academiccrime-says-sultan-perak-KUARCH504228

Chan, C. M., Mat Seman, A. S., \& Shamsuddin, A. (2014). Plagiarism: A review of why Malaysian students commit the academic dishonour. In 2014 International Symposium on Technology Management and Emerging Technologies, pp. 119-122, Bandung, Indonesia. https:/ /ieeexplore.ieee.org/abstract/document/6936490

Cheah J. K. S. (2015). Perspectives on academic plagiarism in Malaysia. In T. Bretag (Ed.), Handbook of academic integrity (pp. 1-4). Springer. https://doi.org/10.1007/978981-287-079-7_5-1

Clark, S. G., \& Wallace, R. L. (2018). The integrity problem in higher education: Description, consequences, and recommendations. Higher Education Review, 50(2), 127-151.

Curtis, G. J., \& Tremayne, K. (2021). Is plagiarism really on the rise? Results from four 5-yearly surveys. Studies in Higher Education, 46(9), 1816-1826. https://doi.org/10.1080/03075079.2019.1707792

Dante, E. (2010, November 12). The shadow scholar: The man who writes your students' papers tells his story. The Chronicle Review. https://www.chronicle.com/article/the-shadow-scholar/

Davis, S. (2021, March 12). Sask. Universities experiencing more academic misconduct as online learning continues. CTV News. https://regina.ctvnews.ca/saskuniversities-experiencing-more-academic-misconduct-as-online-learningcontinues-1.5344891

Drach, I., \& Slobodianiuk, O. (2020). Building a culture of academic integrity in the student environment case of Vinnytsia National Technical University (Ukraine). Creative Education, 11, 1442-1461. https://doi.org/10.4236/ce.2020.118105

Garcia-Carbonell. N., Guerrero-Alba, F., Martin-Alcazar, F., \& Sanchez-Gardy, G. (2021). Academic human capital in universities: Definition and proposal of a measurement scale. Science and Public Policy, 48(6), 877-888. https://doi.org/10.1093/scipol/scab062

Ghazali, A., \& Ghazali, A. (2020). Stretching learning through mapping: The transformative influence of dialogue. International Journal of Education, Psychology and Counselling, 5(37), 108-123. https://doi.org/10.35631/IJEPC.537009

Ghazali, A. (2021). Plagiarists: The dancing shadows ( $3^{\text {rd }}$ ed.). Arniza Ghazali.

Ibegbulam, I. J., \& Eze, J. U. (2015). Knowledge, perception and attitude of Nigerian students to plagiarism: A case study. International Federation of Library Associations and Institutions, 41(2), 120-128. https://doi.org/10.1177/0340035215580278

Ison, D. C. (2014). Does the online environment promote plagiarism? A comparative study of dissertations from brick-and-mortar versus online institutions. Journal of Online Learning and Teaching, 10(2). https://commons.erau.edu/ww-graduate-studies/4

Jereb, E., Perc, M., Lämmlein B., Jerebic, J., Urh, M., Podbregar, I., \& Spraj, P. (2018). Factors influencing plagiarism in higher education: A comparison of German and Slovene $\begin{array}{lllll}\text { students. } & \text { PloS } & \text { ONE, } & \text { 13(8): } & \end{array}$ https://doi.org/10.1371/journal.pone.0202252

Jordan, J., Leliveld, M. C., \& Tenbrunsel, A. E. (2015). The moral self-image scale: Measuring and understanding the malleability of the moral self. Frontiers in Psychology, 6, 1878. https://doi.org/10.3389/fpsyg.2015.01878 
Kok, K. H. (2020). PISA 2018 and Malaysia. International Journal in Advanced Research in $\begin{array}{llll}\text { Education } \quad \text { and } & \text { 2(3), }\end{array}$ https://myjms.mohe.gov.my/index.php/ijares/article/view/10818

Labib, K., Evans, N., Roje, R., Kavouras, P., Elizondo, A. R., Kaltenbrunner, W., Buljan, I., Ravn, T., Widdershoven, G., Bouter, L., Charitidis, C., Sørensen, M. P., \& Tijdink, J. (2021). Education and training policies for research integrity: Insights from a focus group study. Science and Public Policy, 1-21 https://doi.org/10.1093/scipol/scab077

Miller-Young, J., \& Yeo, M. (2015). Conceptualizing and communicating SoTL: A framework for the field. Teaching $\mathcal{E}$ Learning Inquiry, 3(2), 37-53. https://doi.org/10.2979/teachlearninqu.3.2.37

Mohamed, K., Abdul Samat, N. H. A., Abd Aziz, A. S., Mohd Noor, N. A., \& Ismail, N. (2018). Academic plagiarism in Malaysian higher education institutions: Legal perspectives. International Journal of Law, Government and Communication, 3(13), 245-253. http://repo.uum.edu.my/id/eprint/25486

Nabee, S. G., Mageto, J., \& Pisa, S. (2020). Investigating predictors of academic plagiarism among university students. Journal of Learning, Teaching and Educational Research, 19(12), 264-280. https:// doi.org/10.26803/ijlter.19.12.14

Payne, S. L., \& Nantz, K. S. (1994). Social accounts and metaphors about cheating. College Teaching, 42(3), 90-96. https:// doi.org/10.1080/87567555.1994.9926831

Perera, L. D. H., \& Asadullah, M. N. (2019). Mind the gap: What explains Malaysia's underperformance in PISA? International Journal of Educational Development, 65, 254-263. https:// doi.org/10.1016/j.ijedudev.2018.08.010

Perkins, M., Gezgin, U. B., \& Roe, J. (2020). Reducing plagiarism through academic misconduct education. International Journal for Educational Integrity, 13(3), 1-15. https:// doi.org/10.1007/s40979-020-00052-8

Phang, F. A., Khamis, N., Nawi, N. D., \& Pusppanathan, J. (2020). TIMSS 2019 science grade 8: Where is Malaysia standing? ASEAN Journal of Engineering Education, 4(2), 37-43. https://ajee.utm.my/index.php/ajee/article/view/10

Powell, S. (2021, November 25). A new tool to assess research for promotion and recruitment. Nature Index. https://www.natureindex.com/news-blog/new-toolassess-researchers-promotion-recruitment?utm_source=NInewsletter\&utm_medium=email\&utm_campaign=30-November-2021

Ryan, R. M., Williams, J. C., Patrick, H., \& Deci, E. L. (2009). Self-determination theory and physical activity: The dynamics of motivation in development and wellness. Hellenic Journal of Psychology, 6, 107-124. http://selfdeterminationtheory.org/SDT/documents/2009_RyanWilliamsPatric kDeci_HJOP.pdf

Scott, G. (2021, August 16). The Covid-19 aftermath: What the future holds for higher education and the sustainable development goals in a disruptive epoch. Keynote Address. Global Higher Education Forum (Virtual Discourse). Universiti Sains Malaysia.

Sousa-Silva, R., Grant, T., \& Maia, B. (2010). “I didn't mean to steal someone else's words!": A forensic linguistic approach to detecting intentional plagiarism. In $4^{\text {th }}$ International Plagiarism Conference, 21-23 June 2010. http://publications.aston.ac.uk/id/eprint/19304/

Stabingis, L., Šarlauskienė, L., \& Čepaitienė, N. (2014). Measures for plagiarism prevention in students' written works: Case study of ASU experience. Procedia -Social and Behavioral Sciences, 110, 689-699. https:// doi.org/10.1016/j.sbspro.2013.12.913

Tan, K. M., Alyssa-Chua, L-Y., Radzi, M. A., \& Gong, R. (2019). Behind the blackboard: How basic indicators mask gaps in quality of education. Khazanah Research Institute. 
http://www.krinstitute.org/assets/contentMS/img/template/editor/Discussi on \%20Paper_Behind \%20The\%20Blackboard.pdf

Tremayne, K., \& Curtis, G. J. (2021). Attitudes and understanding are only part of the story: Self-control, age and self-imposed pressure predict plagiarism over and above perceptions of seriousness and understanding. Assessment $\&$ Evaluation in Higher Education, 46(2), 208-219. https://doi.org/10.1080/02602938.2020.1764907

Tulus, A. (2020). The relationship between plagiarism and morality. Cienta Moralitas, 57, 56. https:// doi.org/10.5281/zenodo.4385026

Visser, L., Haidegger, T., \& Papanikolopoulos, N. (2012). Pitfalls of publications: On the sensitive issue of plagiarism. IEEE Robotics \& Automation Magazine, 19(4), 85-87. https://doi.org/ 10.1109/MRA.2012.2221239

Watts, T. W., Duncan, G. J., \& Quan, H. (2018). Revisiting the marshmallow test: A conceptual replication investigating links between early delay of gratification and later outcomes. Psychological Science, 29(7), 1159-1177. https://doi.org/10.1177/0956797618761661

Zee, S. V. D., Anderson, R., \& Poppe, R. (2016). When lying feels the right thing to do. Frontiers of Psychology, 7, 734. https://doi.org/10.3389/fpsyg.2016.00734

Zejno, B. (2018). Plagiarism in academic writing among students of higher learning institutions in Malaysia: An Islamic perspective. Journal of Education and Social Sciences, $\quad 9(3), \quad$ 1-4. $\quad$ https://www.jesoc.com/wpcontent/uploads/2018/04/KC9.3_2.pdf 


\section{Appendix 1}

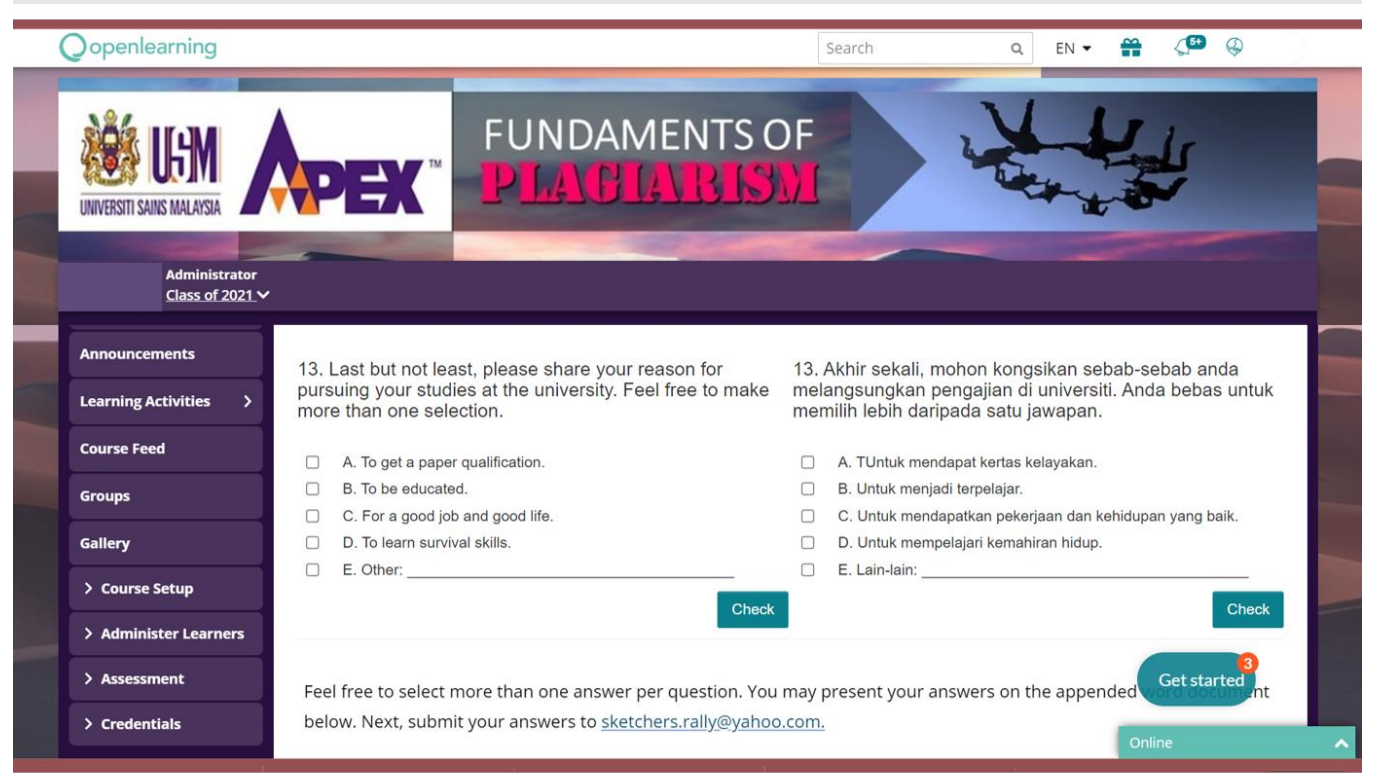

Item 13 was administered for the extended quantitative and qualitative analyses described in section 2.3 .

Complete questionnaire is available at:

https:/ / learning4life.usm.my/courses/fundaments-of-plagiarism 